\title{
Da arte musical como tradução: comentários ensaísticos
}

\author{
Tiganá Neves Santos*
}

O compositor, cantor e violonista brasileiro Roberto Mendes, do munícipio baiano de Santo Amaro da Purificação, lançou, em 2000, um álbum musical duplo intitulado "Tradução". A primeira faixa do álbum é uma recolha de chulas, antes mesmo de que se sigam as suas composições próprias. As chulas, como o próprio artista prefere asseverar, são um comportamento cultural - mais do que um gênero musical - bastante característico de uma região do estado da Bahia conhecida como Recôncavo Baiano. Nelas, há quadras, poéticas, viola, instrumentos percussivos, a conformação geral de roda formada por gente, perguntas e respostas entre cantadores e coro, quem samba (cujos corpos dançam com os pés ligados e reverentes ao chão), palmas de mão. Quanto às contribuições teóricas acerca das chulas, entre alguns trabalhos dedicados, destaquemos aqueles concebidos por pesquisadores e pesquisadoras tais como Costa (2012), Döring (2016a, 2016b), Nobre (2008, 2017), Sandroni $(2005,2010)$ e Sodré (2018). Soa-nos explícita a ideia de tradução para Roberto Mendes, no que tange ao trabalho musical que ele mesmo dirigiu e concebeu, como o seu próprio papel de mediação entre as manifestações matriciais das chulas da sua "terra nativa" e uma recepção de tais manifestações. O músico condensara, no seu violão, na voz, nos seus pendores composicionais uma forma de existir no mundo, sendo o mundo um lugar particular (e, evidentemente, um lugar-encruzilhada atravessado por outras dinâmicas culturais nem todas facilmente identificáveis, já que modos de existir sempre escapam ao caráter finito de uma acepção de objeto de estudo).

\footnotetext{
* Instituto de Estudos Brasileiros/Universidade de São Paulo.
} 
Numa camada um pouco mais submersa (é arriscado afirmar, mas ousaríamos fazê-lo), concede-se que Roberto Mendes perceba a música construída, coletivamente, num comportamento representado pelas chulas, como uma primeira tradução, isto é, qual a leitura de grupos de pessoas por gerações, a fio, quanto ao seu próprio modus vivendi e movimentação do mundo. Nas teorias açambarcadas pelos Estudos da Tradução, de algum modo, aproximar-nos-íamos, se levarmos essas traduções em conta, de uma percepção tradutória intersemiótica, de acordo com o legado fundador de Roman Jakobson, ainda que, a rigor, não estejamos a afirmar aqui o que, quiçá, estivesse alumiado no seu campo de pesquisa e concepção. Os(as) "praticantes" das chulas, como se numa curva histórica (não, necessariamente, em perspectiva sequente), traduzem, isto é, deslocam o real do trabalho, das afetividades, dos desenlaces, da saudade ao canto violado, percutido, sambado. Formam roda para evidenciar a sua leitura consciente e inconsciente do vivido, guardada a pluralidade das pessoas envolvidas em toda a experiência de cultura.

As heranças bantu de parte dos domínios territoriais conhecidos amplamente como Angola assentam-se na chula, no samba de roda (mais genérico) do aludido Recôncavo. Roberto Mendes compila e propõe já outra conformação artística dentro do que Plaza (2003, p.2) destacou como uma interação com um passado que "não é apenas lembrança, mas sobrevivência como realidade inscrita no presente". A esse respeito, o artista e teórico da tradução prosseguiu: "Mas é a visão da história como linguagem e a visão da linguagem como história que nos ajudam a compreender melhor estas relações" (PLAZA, 2003, p.2). Identificamos, no caso das chulas, uma interpretação da sua manifestação fincada nos fatos e na história enquanto linguagem. Coube a Roberto Mendes trasladar tal linguagem que lhe precedeu a uma temporalidade (que também pode ser espaço de acontecimento) expressa sob outro formato e com outras inflexões, o que faz com que esses "originais" permaneçam e repassem seu código genético à descendência, ao tempo em que morrem de si à custa da sua longevidade. Aliás, a tradução intersemiótica nomeada/pensada por Jakobson era também "transmutação". 
Plaza (2003) lembra-nos, ainda, na contextualizada percepção de Walter Benjamin no que toca à história enquanto aquilo que poderia ter sido, numa relevante reflexão, que:

\begin{abstract}
Para o artista-tradutor, a apropriação analógica da radicalidade benjaminiana consuma-se também como uma estratégia poética e política, pois nosso presente aparece alimentado e minado pela contradição entre a intensa consciência do presente que, por querer se afirmar como tal, tende à negação do passado e a impossibilidade de negar o tempo, pois somos seres habitados de tempo. A visão sincrônica da história não seria senão a conciliação sempre provisória dessa contradição. A consciência da história, que data do século XIX e traz consigo inalienavelmente a noção de progresso no tempo, carrega dentro de si a negação dessa noção. A visão sincrônica é a evidência dessa negação e a arte foi a primeira a materializar essa negação no que ela foi imediatamente seguida pela moda. Mas, se esta recupera a história ao nível do consumo, a arte recupera a história ao nível da produção.

Assim, toda produção que se gera no horizonte da consciência da história problematiza a própria história no tempo presente [...] Se, num primeiro momento, o tradutor detém um estado do passado para operar sobre ele, num segundo momento, ele reatualiza o passado no presente e vice-versa através da tradução carregada de sua própria historicidade, subvertendo a ordem da sucessividade e sobrepondo-lhe a ordem de um novo sistema e da configuração com o momento escolhido.

No processo dialético e dialógico da arte não há como escapar à história. A arte se situa na urdidura indissolúvel entre autonomia e submissão. Filha de sua época, a arte, como técnica de materializar sentimentos e qualidades, realiza-se num constante enfrentamento, encontro-desencontro consigo mesma e sua história. Parafraseando Marx: os artistas não operam de maneira arbitrária, em circunstâncias escolhidas por eles mesmos, mas nas circunstâncias com que se encontram na sua época, determinadas pelos fatos e as tradições. (PLAZA, 2003, p. 5)
\end{abstract}

Debruçar-se, portanto, sobre a tradição condutora é, no âmbito da arte tradutora, reler as ressonâncias (numa perspectiva benjaminiana-bermaniana) e lançar novas ondas ao (des)conhecido, configurando, assim, de maneira movente e muitas vezes perturbadora, entre a dependência e a incontornável iconoclastia, uma espécie de continuum da inventividade da própria história a partir das marcas e marcos artísticos. É como se um artista qual Roberto Mendes, nosso pregoeiro a ratificar uma análise da arte musical como fato tradutório, apresentasse saudade e fome, termos que na língua 
bantu kikongo, também presente no norte da já referida Angola originária, são o mesmo, isto é, nzala. Rezar é samba, quer na língua kikongo, quer na sua língua-irmã kimbundu, ainda mais restrita à nação angolana. Há uma sacralidade nessa tradução artística do mundo, a qual, por seu turno, foi traduzida e recolocada por Roberto Mendes. O samba de roda, no qual se desvela a chula, é um culto aberto, cifrado e exposto, haja vista o templo ser a própria ocupação do mundo por parte de quem o pratica. Empunhar a enxada e tanger as cordas da viola machete são ações mutuamente suplementares para quem existe. É como um "viver que vai entre o que vive" na narrativa fluvial de João Cabral de Melo Neto; há diferenças, mas não há relevos assimétricos entre os afazeres. A sacralidade, deste modo, consiste em que tudo é insofismavelmente ordinário.

Se adentrarmos um pouco mais o universo cosmológico bantu, particularmente, o universo kongo, em que traduzir é sekola, ou seja, lidar com kolo - código, nó, embrulho cifrado - no tempo (kolo), no instante (kolo), dentro de uma trajetória de maturação (nkola), notaremos que ativar ou desativar (kala-zima) o que seja é algo do domínio e tecido das ondas e radiações (minika ye minienie), de acordo com essa mundividência. A memória e a invenção ou para fundir-nos às palavras da canção de Roberto Mendes e Jorge Portugal, "o inventário e o inventar" da canção "Esse sonho vai dar", são reverberações de ondas e radiações. Dizer palavras nas línguas dos antepassados e evocar-lhes as tradições (com toda a sua movimentação incontível, claro) é acionar esse princípio bantu-kongo tão caro e fundante. Firmase o corpo sonoro da palavra antes do que se dá a ver. De acordo com o pesquisador argentino Adolfo Colombres:

\footnotetext{
No pensamento bantu, a imagem não é anterior à palavra, já que é o nommo ${ }^{1}$ que engendra a imagem da coisa, tão logo tenha criado a coisa. Ao nomear o objeto ausente, a palavra transforma-o em imagem ou $s e^{2}$ transforma em imagem. Isto quer dizer que, no fim das contas, não há mais que palavras, e a boa palavra é como a chuva: sempre desejada e bem-vinda ${ }^{3}$. (COLOMBRES, 2010, p. 35)
}

\footnotetext{
${ }^{1}$ Grifo do autor.

${ }^{2}$ Grifo do autor.

${ }^{3}$ Originalmente: En el pensamiento bantú, la imagen no es anterior a la palabra, ya que es el nommo quien engendra la imagen de la cosa, luego de haber creado la cosa. Al nombrar el objeto ausente, la palabra lo transforma en
} 
Salientemos a capacidade de a palavra, enquanto um dos eixos fundamentais da oralidade, chegar ao tempo presente, ao instante, na dimensão do acontecimento. Por intermédio da enunciação física de uma palavra kongo, as ondas e radiações - sobretudo, as ondas - trazem-nos uma dimensão kongo, uma vivência de sentidos kongo, tanto quanto nos seja possível, do nosso lugar de recepção e interpretação.

O filósofo Eduardo Oliveira, ao analisar aspectos da epistemologia africana dogon (dentro da acepção de "epistemologia - e filosofia - da ancestralidade" por ele cunhada), estabelecendo certo diálogo com o antropólogo Marcel Griaule e a antropóloga Germaine Dieterlen, notáveis investigadores da cosmologia dos dogon, do Mali, conduz-nos à especial reflexão quanto ao conceito (e à experiência) de vibração. Esta "anima a existência" e se pode desdobrar, irradiar, a partir do humano seminal, conforme observamos no contexto bantu-kongo. Afirma Oliveira (2017):

\begin{abstract}
A pequena semente é ao mesmo tempo a menor parte do universo e o universo inteiro posto que se alastra por todo planeta, germinando-o. Diferentemente das metafísicas que concebem o Ser como uma mônada, seja ela estática ou dialética, os Dogon entendem que o que anima a existência é uma vibração $0^{4}$. Já os Bantos - cf. Pe. Altuna - concebem a Força Vital como a energia que anima o mundo. Se isto é uma verdade no Sul da África, o é também na África Setentrional (por exemplo, entre os Dogon). Pensa-se a existência a partir de uma vibração, da energia e da emanação. A fonte dessa metafísica que é mais uma infra-física nos permitirá elencar mais um princípio fundamental da Forma Cultural Africana, a saber: O Princípio da Emanação. (OLIVEIRA, 2017, p.5-6).
\end{abstract}

Não colocaríamos aqui como contrastivas a "Força Vital", resgatada por Eduardo Oliveira da afirmação de Raúl Altuna, e a "vibração" dogon. As ondas e radiações bantu constituem tal força. O movimento, as transmutações, o que permanece, o que se desconhece, o que se experiencia, o que se virtualiza, tudo, substanciando e sendo substanciado por essa força, acontece de modo vibrátil. O ser humano (muntu) é síntese dessa dinâmica porque a

imagen, o se transforma en imagen. O sea que, al fin de cuentas, no hay más que palabras, y la buena palabra es como la lluvia: siempre deseada y bienvenida

${ }^{4}$ Os grifos deste excerto são do autor. 
vive-pensa e dela emana, assim como enxerga Oliveira (2017) no exemplo dogon:

\footnotetext{
O homem é síntese do processo de germinação da semente, o universo síntese da germinação humana e tudo é processo iniciado e veiculado pela vibração que anima tanto a pequena semente quanto a imensidão do universo. Cada qual é processo em si mesmo e síntese do outro. Toda essa dinâmica é relacional, processual, e sua dinâmica articula a singularidade da existência territorializada como a cosmovisão da cultura estruturante. Ao mesmo tempo cada qual é inteiro o que se é! Mais!, ao mesmo tempo é coisa e símbolo, signo e objeto, fagulha e escuridão. Ao mesmo tempo, e encerrados no mesmo instante, é-se processo e evento, acontecimento e passado, acontecimento e futuro. É-se realização e possibilidade, desconstrução e construção, criatividade e conservação. (OLIVEIRA, 2017, p. 7)
}

Para que o existente cumpra sua vocação para a transmutação (nsoba) é necessário que vibre (tatala). O existir parte do humano, mas deve expandir-se para o extra-humano, muitas vezes, sendo o extra-humano anterioridade geratriz do humano. Pode, assim, vir antes, ainda que por meio do humano, todo um fio de memória a se reportar à "categoria analítica" (OLIVEIRA, 2017) da ancestralidade. A memória viceja no tempo presente - eis onde vige o ancestral - como ntima, mesmo termo, em kikongo, para coração, assim como nos desenhos etimológicos latinos, nos quais "saber de cor" é "saber de coração". A memória vibrátil é encarnada pelo que pulsa no tempo, sangra, dilata-se, comprime-se, não pode parar, sendo das interioridades mais individualizadas e, simultaneamente, o mesmo princípio em qualquer pessoa.

A memória, assim como a invenção, a arte, a música, os rituais e as pessoas, têm ritmo, o qual, por seu turno, indica uma figuracão de temporalidade. Se preferirmos, é estar no tempo de determinada maneira. Kumu, termo para ritmo, manifesta-se por meio de alguma sequência temporal, que, para ser sequência, implica ter marcações ao longo do corpo do tempo. Essas marcações podem ser reconhecidas como eventos do tempo. E eventos do tempo são códigos por meio dos quais o próprio tempo se vai mostrando. 
Deste modo, os códigos (kolo) ${ }^{5}$, que são uma dimensão não submersa do próprio tempo, fazem-se lugares onde o tempo repousa. Interessantemente, os termos para ritmo, kumu, e lugar, kuma, têm raízes comuns. O tempo é o lugar de ocorrência das coisas. O ritmo é um lugar possível do tempo. Quando ouvimos ou sentimos uma pulsação rítmica, temos ali conosco onde o tempo mostra que existe, veste-se de evento e comunica-se de modo identificável, isto é, mostram-se resultados de frequências.

A música oferece uma estética mais evidente ao ritmo; estética não acessória. Cantar (yimbila), por exemplo, é emitir linhas de força de determinada forma, a fim de enunciar coisas no e do mundo, a partir de uma disposição que a palavra falada, por vezes, não pode ocupar. Cantar pode, na direção contrária à de muitas palavras que trazem o intangível ao tangível, fazer com que nos comuniquemos com o que não tem concretude; pode fazer com que saiamos do corpo material e cheguemos à intenção, ao sentimento, ao insondável. Trata-se de uma realização por desrealização; ao passo que outros sons, muitas vezes, podem precipitar coisas que vêm de não coisas. Quando se está na música, tem-se a certeza de que o som ordinário pode tanto ser quanto nos conduzir ao extraordinário. Cantar não é a fala comum; é lembrar da temporalidade sobre a qual o som pode deitar-se, bem como do fato de que fazer a voz agir é ter uma intenção, quase química, de ver reagirem elementos a outros que provocam tais reações. Saber lidar com essa comunicação química é especializar-se na própria existência, já que vivemos para compreender o que emitir à vida e o que dela receber de volta (tambula ye tambikisa); e paralelamente, ao receber da vida, entender sobre o que the responder. Os bantu nos parecem dar a responsabilidade por nossas próprias construções, e, no fundo, dizem-nos que desembainhamos o mundo da nossa interioridade. Há um encadeamento tradutório em que as ondas e radiações são os vetores transversais, do insondável ao humano-vida, do ritmo-temporalidade de como se vive à estética musicada do ritmo como pegadas do transcurso do tempo. A ação tradutória humana munida de alguma (ainda que recuada quanto a uma intenção nominável) consciência, no qua-

\footnotetext{
${ }^{5}$ Kolo, entre a civilização bantu-kongo, também traz a ideia, assim como tandu, de tempo histórico (ou seja, época, geração etc.), de acordo com o pensador congolês Bunseki Fu-Kiau.
} 
dro do encadeamento a que fazemos alusão, ao que parece, advém do(a) artista: tradutor(a) universal, segundo Octavio Paz. Os demais atos tradutórios que enunciamos são obra de nossa interpretação de um mundo inexplicavelmente sistêmico, no que apresenta de ontologicamente opaco, já que não veio de nós, e no que carrega da nossa proposta (talvez, orgânica) do que seja o mundo. Concebendo o existir necessariamente com quididade ontológica humana, o que há é linguagem:

\footnotetext{
A linguagem não se responsabiliza apenas por produções que respondem à necessidade de sobrevivência física (objetos, vestimentas, arquiteturas etc.), mas também a necessidades impostas pela sobrevivência psíquica. Os rituais, deuses e mitos, o canto, a música, os jogos, as primeiras inscrições devem ter a mesma antiguidade do homem. (SANTAELLA, 1996, p. 166)
}

Linguagem são interlinguagens. O traduzir intersemiótico, portanto, é deslocamento de um complexo em interação a outra expressão de complexidade, ao estabelecimento de novas relações que geram textualidades distintas das inscrições-fonte. Ao tempo em que se incorpora uma síntese presente, abre-se um portal de transbordo, torção, quebra, reconhecimento do que precede e recusa a qualquer possibilidade de que desponte a sua subjacência.

No Brasil musical, o exemplo de um Dorival Caymmi tradutor é lapidar. O cantautor soteropolitano, falecido em 2008, que, segundo o músico Egberto Gismonti, propôs, ao lado de Luiz Gonzaga, os caminhos do cancioneiro gravado no país, traduziu intersemioticamente as manifestações populares, sobretudo, da praieira, pesqueira, negra Salvador das religiões de matrizes africanas e do catolicismo popular. Caymmi, que também era pintor (assim como o compositor carioca Heitor dos Prazeres), trouxe imagens, comportamentos, modos de falar, ou seja, linguagens originárias e verteu-os em ideias lítero-musicais; transmutou-lhes as frequências (ondas e radiações - minika ye minienie) em canção (e pintura). Pesquisas de relevância como as de Caymmi (2001), Carvalho (2015) e Garcia (2017) mostram o caráter tradutório do compositor, no que tange a sua relação com culturas populares, se levarmos em conta a análise que estamos a explicitar. 
Roberto Mendes, na segunda parte do álbum "Tradução", dedica-se, quase absolutamente, ao registro musical de algumas manifestações da cultura popular de uma parte da Bahia, evidenciando, ainda mais, as fontes a partir das quais exerceu o seu traduzir. Ressaltemos o caráter intersemiótico do seu traduzir pelo fato de expressões culturais como a "Burrinha", "Partilha de Boi" ou "Sambas de Xaréu" serem mais do que música. Para que entremos em tal universo é necessário que não desassociemos os resultados musicais do labor, da religiosidade, da estética, da linguagem falada - e para irmos mais adiante, da própria topografia, do tipo de terra que se cultiva e onde se vive. A tradução de Roberto Mendes, forçosamente, é de toda essa conjuntura inseparável e sem fronteiras ou compartimentos de distinção. O violão, como de fato ocorre no caso desse músico-tradutor, deve traduzir a resistência (e técnica) empregada na enxada, assim como esta deve ter o ritmo exigido de uma viola para que ancore o tempo. O crítico musical Tárik de Souza escreveu no encarte do álbum musical em questão:

\begin{abstract}
Este CD duplo traz num dos anzóis exemplares autênticos da chula, o samba do recôncavo baiano (das regiões canavieiras de Santo Amaro e Cachoeira) executado por grupos da região e no outro a transfiguração desse universo através de temas de Mendes com os parceiros Jota Velloso, Chico Porto, Nelson Elias e Jorge Portugal. (MENDES, 2000)
\end{abstract}

O supracitado crítico musical traz-nos o termo "transfiguração" para o que apresentamos e absorvemos como tradução na nossa forma de abordar uma parte do exemplo narrativo de Roberto Mendes. A mudança de figuração, partindo-se de um comportamento cultural, pode ser um bom desenho semântico a retomar a dimensão bantu em que sons desdobram-se, inescapavelmente, no distinto em relação ao originário. Podemos perceber a explicitação do argumento artístico de Mendes (2000) ao intitular "Tradução" um álbum que reproduz musicalmente modos ancestrais de ser e criações musicais advindas dessas ocupações culturais primeiras. A tradução dá-se quando assumido o caráter apriorístico do que está em relação. Talvez, por esse motivo, para tratar de uma conformação cultural do Brasil como um todo, isto é, para traduzi-lo como nação - e lembremo-nos aqui da sentença bantu que diz que "nações são florestas" - na canção "Manda chamar", 
Mendes (2000), em parceria com Capinam, evoca: “Manda chamar os índios, manda chamar os negros, manda chamar os brancos, manda chamar meu povo para o rei Brasil renascer, renascer de novo". Esse Brasil soa equivaler ao que, num álbum de 1994, o cantautor, ao lado de Jorge Portugal, chamou de "Yorubahia" (uma hialina justaposição da presença iorubana no Brasil a uma nação sintetizada na cultura baiana) e designou, textualmente, como "signo tradutor". As vozes que enunciam o extraordinário advindo do ordinário, na segunda parte do álbum duplo a que nos referimos com centralidade, são praticamente todas de uma estampa sociocultural que gerou o artista-tradutor Roberto Mendes. Não são vozes dele, mas vozes que estão nele. $\mathrm{O}$ tradutor não traduz algo que, de algum modo, não leve consigo antes e depois do (f)ato de traduzir. Além de cantares ancestrais (e aí não se trata mais das composições de Roberto Mendes), a maior parte das faixas dessa segunda parte da obra inicia-se pela explicação de uma pessoa "mais velha" (como sociedades negro-africanas e afrodiaspóricas concebem) sobre o que será cantado e que lugar ocupa na perspectiva do seu pertencimento. De certo modo, os originais explicam a sua primeira camada de tradução (no que diz respeito a um modo de existir), e Roberto Mendes, por seu turno, transmuta musicalmente tal modo de existir. $\mathrm{O}$ artista assume todo esse processo sob o título que já evidenciamos ("Tradução"), eis por que trazer algo da sua obra para a nossa reflexão condensada nestas páginas. Fizemos alusão à emblemática última canção do álbum, "Esse sonho vai dar", quando versamos sobre memória e invenção anteriormente. Retomemos um questionamento relevante presente nas suas primeiras palavras (cantadas): “Não há nada de novo, por que não cantar?". Os diversos construtos tradutórios e do âmbito do criar provêm de toda uma rede de sentimentos, ideias, corpos, entes, formas de ser antecedentes. Traduz-se e cria-se justamente pelo fato de tudo já estar dado e posto como uma espécie de "ser imóvel" proposto pelo pensamento do filósofo grego Parmênides de Eléia. A imobilidade do que está posto deve-se ao fato de ser impossível percorrermos as sendas do que não é. A invenção lançada pela memória, portanto, não alcançaria a novidade ontológica, mas a diferença, uma forma distinta de ser e se colocar no mundo. 
Este texto é mais uma intuição tradutória, guardadas as opacidades e o que não está resolvido, do que uma investigação acerca de competências tradutórias ou resultados de tradução e versão musical. Determinadas chaves de pensamento e realidade nos traduzem ao seu mundo, antes que o façamos. Essa tradução mútua implica chegarmos a outros modos de vivenciar as relações. As alteridades não são, definitivamente, o que delas pensamos, ainda que seja essa uma dimensão relevante quanto às ocorrências éticas. As alteridades culturais são solitárias no que concerne as suas configurações e experiências próprias. Contudo suas configurações são, necessariamente, linguagens entretecidas. Traduzir é transformar um tecido noutro tecido com espaços vazios e formas de ocupar e criar mundos. Em outras linguagens artísticas (e ainda na música), foi o que fizeram, ao seu modo, voz e tempo, por exemplo, Aimé Césaire, Herberto Hélder, Loïs Mailou Jones, Escher, Clarice Lispector, Glauber Rocha, Noémia de Sousa, Nina Simone, Paul Valéry, Guimarães Rosa, Mishima, John Coltrane, Machado de Assis, Clementina de Jesus, Hilda Hilst, João Gilberto, Elsie Houston, Conceição Evaristo, Mercedes Baptista, Ruth de Souza, Milton Nascimento. Traduzir são linguagens entre linguagens e toda a porosidade que há em sê-lo.

\section{Referências}

CARVALHO, Marielson. Caymmianos: personagens das canções de Dorival Caymmi. Salvador: EDUNEB, 2015.

CAYMMI, Stella. Dorival Caymmi: o mar e o tempo. São Paulo: Editora 34, 2001.

COBE, Francisco Narciso. Novo dicionário português kikongo. Luanda: Mayamba, 2010.

COLOMBRES, Adolfo. Celebración del lenguaje: hacia una teoría intercultural de la literatura. Buenos Aires: Ediciones del Sol (Serie Antropológica), 2010.

COSTA, Alex Augusto Mesquita. Recôncavo baiano: catalogação de elementos musicais idiomáticos para o ensino de violão e guitarra. Dissertação (Mestrado em Educação Musical). Universidade Federal da Bahia, Escola de Música, 2012, 337f. 
DÖRING, Katharina. Cantador de Chula: o samba antigo .... Serie sons da Bahia. Salvador: Pinaúna Editora, 2016a.

. A cartilha do Samba Chula. Salvador: Umbigada, 2016b.

FU-KIAU, Kimbwandende kia Bunseki. African cosmology of the bantukongo: principles of life and living. 2.ed. Nova Iorque: Athelia Henrietta Press, 2001.

GARCIA, Walter. Melancolias, mercadorias: Dorival Caymmi, Chico Buarque, o pregão de rua e a canção popular-comercial no Brasil. Cotia: Ateliê, 2017.

JAKOBSON, Roman. On Linguistic Aspects of Translation. In: VENUTI, Lawrence (ed). The Translation Studies Reader. Londres: Routledge, 2000. Linguística e comunicação. Tradução de Izidoro Blikstein e José Paulo Paes. 22.ed. São Paulo: Cultrix, 1976.

MENDES, Roberto. Tradução (álbum 1). São Paulo: Atração Fonográfica, 2000. Disponível em: https://www.youtube.com/watch?v=qozZENkKtH4. Acesso em abril de 2019.

Tradução (álbum 2). São Paulo: Atração Fonográfica, 2000. Disponível em: https://www.youtube.com/watch?v=1Du7gDXtv7w. Acesso em abril de 2019.

NOBRE, Cássio. Samba chula enquanto world music: políticas públicas e produção fonográfica no samba de roda do Recôncavo Baiano. Tese (Doutorado em Música). Universidade Federal da Bahia, Escola de Música, 2017.

Viola nos sambas do Recôncavo baiano. Dissertação (Mestrado em Música). Universidade Federal da Bahia, Escola de Música, 2008.

OLIVEIRA, Eduardo. Epistemologia da ancestralidade. Disponível em: https://filosofia-africana.weebly.com/uploads/1/3/2/1/13213792/eduardo_oliveira_-_epistemologia_da_ancestralidade.pdf. Acesso em abril de 2019.

PLAZA, Julio. Tradução intersemiótica. São Paulo: Perspectiva, 2003.

SANTAELLA, Lúcia. Cultura das mídias. São Paulo: Experimento, 1996.

SANDRONI, Carlos. Questões sobre o dossiê do samba de roda. Registro e Políticas de salvaguarda para as Culturas Populares, Rio de Janeiro, Iphan, "Série Encontros e Estudos", n.6, p.45-53, 2005. 
. Samba de roda, patrimônio imaterial da humanidade. Revista Estudos Avançados. n. 24, vol. 69, p. 373-388, 2010.

SECCHIN, Antônio Carlos (Org.). Melhores poemas de João Cabral de Melo Neto. São Paulo: Global, 2003.

\title{
Resumo
}

Neste texto, tenciona-se refletir acerca da arte musical enquanto tradução de realidades, sobretudo, culturais (na sua dimensão histórica). Como exemplo do que se aspira a analisar, recupera-se a experiência do artista baiano Roberto Mendes qual tradutor de chulas do Recôncavo Baiano, em grande parte da sua obra, as quais representam, mais do que um gênero musical, um comportamento cultural complexo. Tal processo tradutório, explícito num álbum musical intitulado "Tradução", aproxima-se do que se pode compreender como tradução intersemiótica. Referências cosmológicas africanas bantu, entre outras, auxiliam esta análise.

Palavras-chave: Arte musical; Tradução intersemiótica; Roberto Mendes; Cosmologia bantu.

\begin{abstract}
This text aims to reflect on musical art as translation of realities, especially cultural ones - regarding their historical dimension. As an example of what one aspires to analyze, the experience of the Bahian artist Roberto Mendes is reestablished, since he is a translator of chulas - and the chulas of Recôncavo Baiano are more than a musical genre, because they are a complex cultural behavor. Such a translational process found explicitly in the album called "Tradução" is similar to what can be understood as intersemiotic translation. Bantu African cosmological references, among others, support this analysis.
\end{abstract}

Keywords: Musical art; Intersemiotic translation; Roberto Mendes; Bantu cosmology. 